\title{
5200 Evaluation of a large volcanic gas play in the northern Songliao Basin, Northeast China
}

Stefan Luthi* (Delf University of Technology), Li GuoXin (PetroChina Beijing), Wang

YuHua, Yang FengPing and Zhao Jie (PetroChina DaQing), Jeff Meisenhelder, Sherif Farag, Yang XingWang, Zhu YouQing, Hou Hui Jun, Zhang Shu Pin, Wu Chuan, and Wu Jie Hui

(Schlumberger Oilfield Services Beijing), Thomas J. Neville (Schlumberger Beijing

Geoscience Center) and Michael Conefrey (consultant).

Discovery of a gas accumulation in Lower Cretaceous volcanic rocks in the Songliao Basin, Northeast China, has led to a thorough evaluation of the prospect with the goal of assessing its economic viability. In total 15 fully logged and partially cored wells were analyzed, together with $915 \mathrm{~km} 2$ seismic. A logging suite that includes geochemical logging, NMR measurements and borehole imaging is found to be best suited for evaluating these unusual reservoir rocks. The gas accumulation is contained in rhyolitic pyroclastics and lava flows, and subordinately in the overlying conglomerates. The volcanic sequence structure forms a saddle along a fault where the volcanic vents were located, forming a pearl-string like arrangement of domes. Trapping conditions are best described as combined stratigraphicstructural, since no full closure of the structure exists. It is likely that the increasing shale content of the overlying conglomerates acts as a progressively tightening seal. The coalbearing strata in the underlying Jurassic sediments are considered to be the source rock. The volcanics consist in about equal parts of rhyolitic lavas and pyroclastics, with the first ones being more abundant in the vicinity of the vents, and the latter often blanketing the depressions. The initial volcanic, however, was dominated by basaltic lava flow. Periods of volcanic quiescence resulted in erosion and sedimentary deposits in the lower reaches, mostly of fluvial and lacustrine nature. The vertical and lateral distribution patterns of the volcanic lithofacies allows a fairly accurate reconstruction of the sequence of volcanic events, which forms the basis for a reservoir model. Porosity is found to be vesicular and fractured in the lava flows, and microporous, vuggy and leached in the pyroclastics. The latter happened preferably with pyroclastic deposits that were exposed to erosive forces; they form the best reservoir rock types, whereas the rhyolitic lava flows are found to be the worst. Petrophysical analyses indicate that the volcanics lie throughout their entire thickness of up to 700 feet within a capillary transition zone, mostly because of the very narrow pore throats. Saturations therefore have to be obtained from a saturation-height function above free water level in combination with the capillary pressure curves obtained in the laboratory for the various lithofacies. These relationships of the various lithofacies are used to populate the reservoir model with petrophysical properties in a semi-deterministic way. This model was used to calculate reserves in-place and showed the accumulation to be economic. The field is currently being put in production to serve the nearby city of Harbin in the province of Heiljongjan.

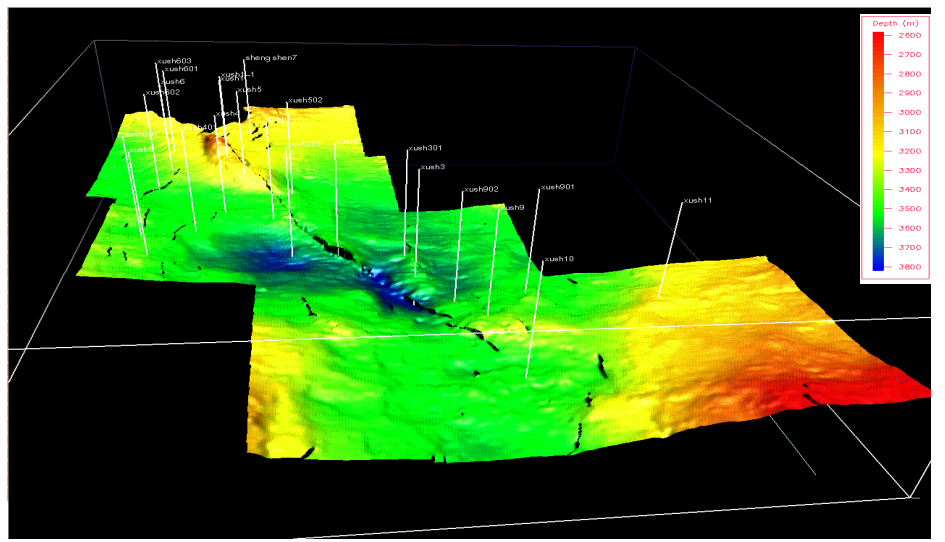

Structure map of the top of the volcanic sequence with the well locations. 